\title{
WILL THE TRADITIONAL MEDICINE UN-PAUSE THE WORLD AND DECIDE THE FATE OF COVID-19?
}

\author{
JANANI S. K. ${ }^{1}$, DHANABAL S. P. ${ }^{2}$, SURESHKUMAR R. ${ }^{3 *}$, CHENMALA KARTHIKA ${ }^{4}$, SAI SURYA NIKITHA \\ UPADHYAYULA ${ }^{5}$
}

1,3*,4,5Department of Pharmaceutics, ${ }^{2}$ Department of Pharmacognosy and Phytopharmacy, JSS College of Pharmacy, JSS Academy of Higher Education and Research, Ooty 643001, The Nilgiris, Tamil Nadu, India

Email: sureshcoonoor@jssuni.edu.in

Received: 30 Nov 2020, Revised and Accepted: 12 Jan 2021

ABSTRACT

COVID-19 is a life-threatening disease that mainly affects the human respiratory system. In today's world, scientists are working conscientiously for the identification of promising drugs and vaccines. But, when we look back to the former times, herbal medicines were considered for curing most of the diseases; luckily, nowadays, natural remedies are being carried forward by few researchers even for the treatment of most life-threatening diseases like cancer, diabetes and alzheimer's etc. So, why can't we attempt the herbal formulation for the management of COVID-19 too? Since there is no proper scientific validation for traditional herbs and spices; it just can't be simply ignored. When a product with less or few side effects can be prepared and made available for the benefit of people, there is nothing wrong in pondering them. Thus, keeping these points in mind, in this article, we have discussed about SARS CoV-2, their treatment options and the impact of natural remedies on both the former as well as novel coronavirus. Further, we have also emphasized on traditional Chinese medicine, various flavonoids and kabasura kudineer and their impact on coronavirus infection. Till now, there is no particular drug or vaccine available for the treatment of COVID-19; thus prevention is the only option. But, we hope that thorough study; screening, preclinical and clinical evaluation of natural compounds may give some action against SARS CoV-2. Moreover, incorporating natural herbs and spices in our diet can help in boosting immunity and fight against various life-threatening diseases.

Keywords: COVID-19, Flavonoids, Kabasura kudineer, Traditional medicine, Traditional Chinese medicine

(c) 2021 The Authors. Published by Innovare Academic Sciences Pvt Ltd. This is an open access article under the CC BY license (https://creativecommons.org/licenses/by/4.0/) DOI: https://dx.doi.org/10.22159/ijap.2021v13i2.40413. Journal homepage: https://innovareacademics.in/journals/index.php/ijap

\section{INTRODUCTION}

Currently, most of the people are being affected with the well know disease called COVID-19. This disease in recent times has shaken the world. SARS-CoV-2 mainly affects the human respiratory system. It belongs to the family Coronaviridae that consist of single-stranded RNA, a positive sense enveloped in the nucleocapsid [1]. Structure of SARS-CoV-2 is given in (fig. 1).

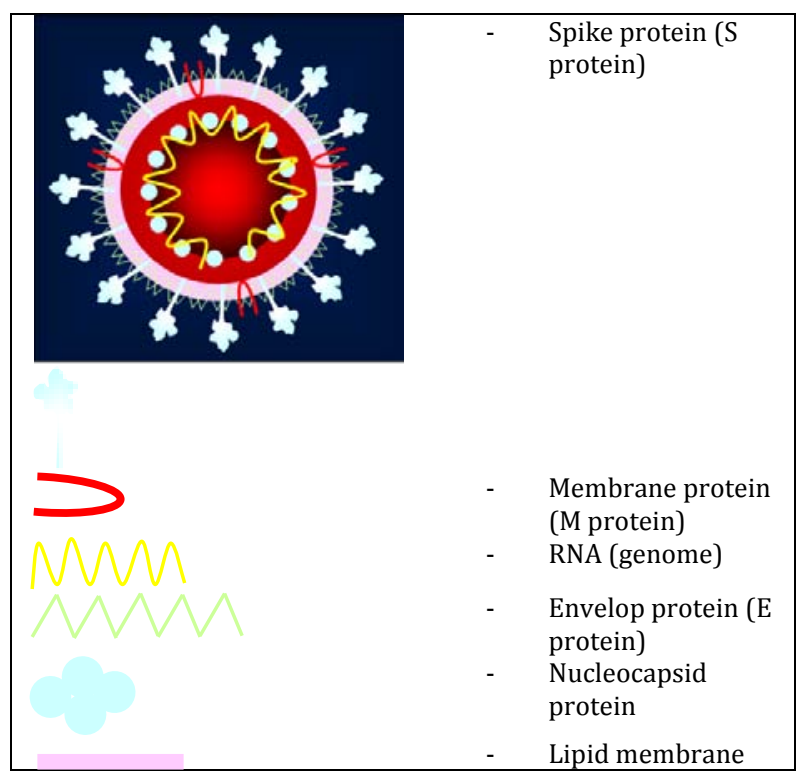

Fig. 1: Represents the structure of SARSCoV-2: It contains positive-stranded RNA (sense) that is enclosed in the nucleocapsid, membrane protein, envelop protein and most importantly the spike protein (glycoprotein) that binds to the receptor present on the human cell [8]
Since, it is a contagious disease, its outbreak is worst and developing a treatment option is also a challenging one. This particular viral infection is similar to the former coronavirus infections namely SARS$\mathrm{CoV}$ (Severe acute respiratory syndrome coronavirus) and MERS-CoV (Middle East respiratory syndrome coronavirus). According to the National institute of allergy and infectious diseases, SARS-CoV was first reported in 2003 in Asia that led to severe viral respiratory illness. Followed by MERS-CoV, which is a respiratory disease that was first reported in Saudi Arabia in 2012 [2]. In that list, SARS-CoV-2 is also a respiratory viral infection that was first originated in Wuhan City on $31^{\text {st }}$ December 2019. Since then the causative agent for the disease was unknown. Thus, they have classified this disease as pneumonia with an unknown etiology. However, there is a conjecture that it has an animal origin [3]. In this article, we have discussed about the virus, its replication cycle and finally, the treatment options. We have also shed a light on the traditional medicine and kabasura kudineer used in the management of coronavirus infection.

Epidemiology, incubation period and treatment options

When we look into epidemiology, countries like India, USA, Russia, Iran, Italy, and China are more prone to this disease and the mortality rates are also high [4]. According to WHO (World Health Organization), the globally confirmed cases are 6,23,63,527 and confirmed deaths are $14,56,687$ as of $30^{\text {th }}$ November 2020 [5]. Graph representing the case comparison (confirmed cases as of November 30,2020 ) of WHO regions are given in (fig. 2) [6].

Studies show that the spreading of SARS-CoV-2 is due to person-toperson transmission. This particular transmission is due to direct contact with the affected individual or via the droplets that spread through coughing and sneezing from the affected individuals [7]. The evolution of virus needs some incubation period. Literature state that the mean incubation period is estimated to be 3-7 d ranging from 2 to $14 \mathrm{~d}$ [8]. However, WHO states that it can range from 1-14 d [9]. While coming to the diagnostic tests for COVID-19, it includes RT-PCR (reverse-transcription polymerase chain reaction), rRt-PCR (real-time reverse transcription PCR) and RTLAMP (reverse transcription loop-mediated isothermal amplification)[10]. When we look into the treatment options, as of 
now, there is no particular vaccine or drug available for complete rehabilitation. However, researchers are putting their effort to find a promising solution for this. In that case, various drugs like dexamethasone, lopinavir/ritonavir, remdesivir and neuraminidase inhibitor including oral oseltamivir and zanamivir [11] are tested against COVID-19 but most of them fail to meet the complete therapeutic action due to various reasons like the structure of virus, toxicity of drug and side effects. However, clinical trials for various drugs like decitabine, infliximab and deferoxamine are being carried out to find an appropriate medication [12].

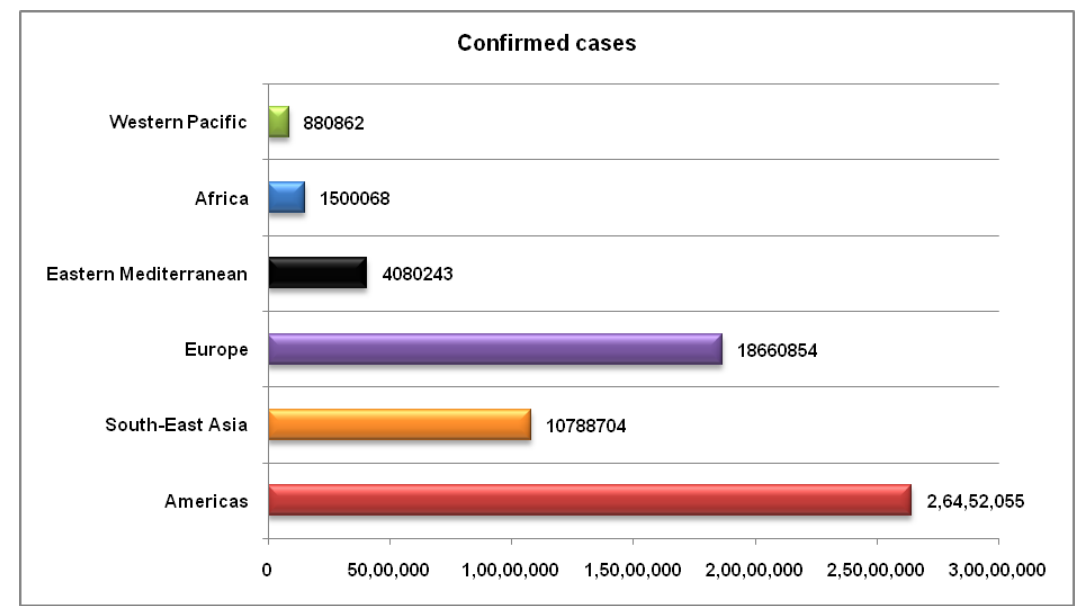

Fig. 2: Graph representing the case comparison (confirmed cases as of November 30, 2020) of WHO regions

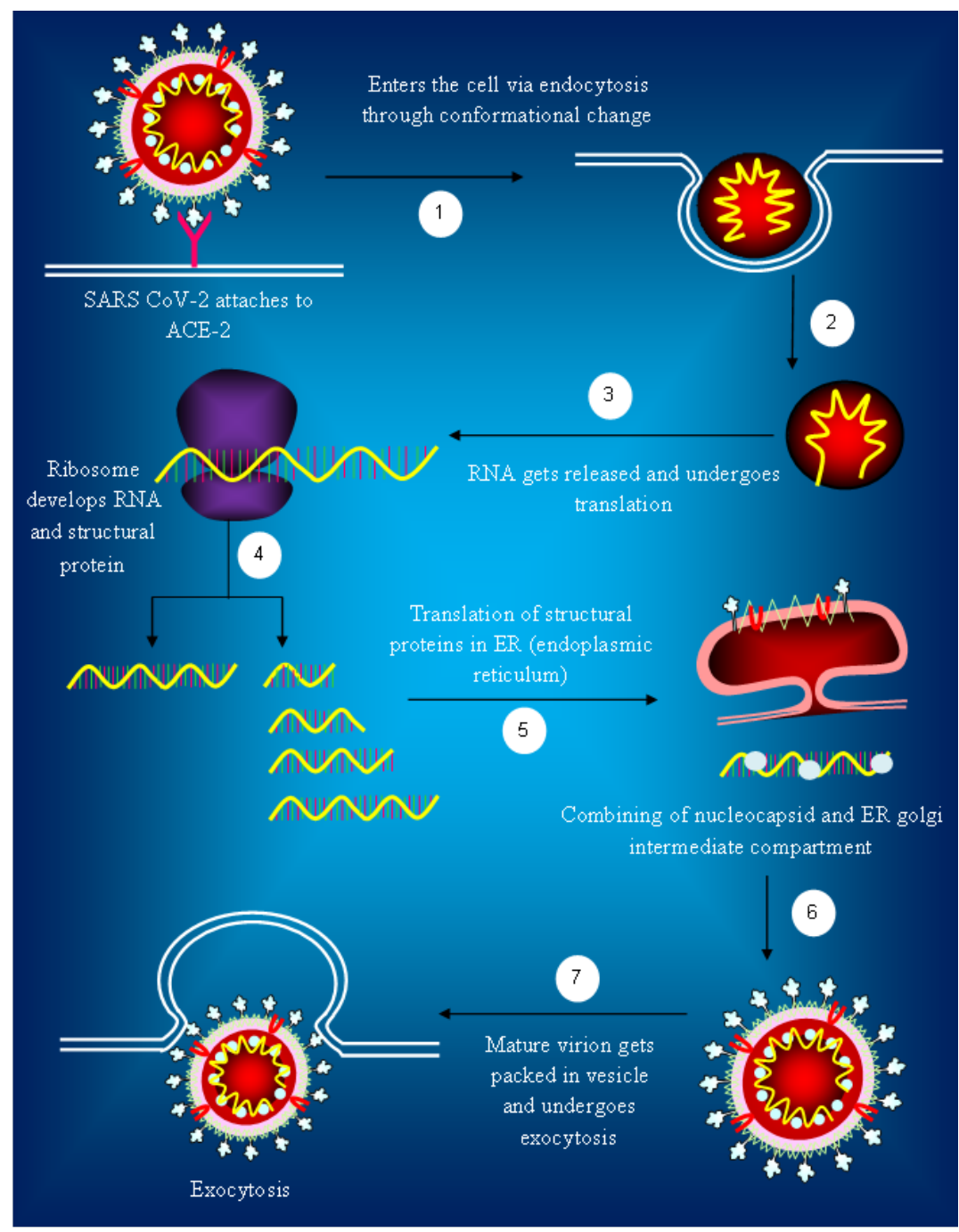

Fig. 3: Represents the replication process of SARS CoV-2 


\section{Pathophysiology and replication of SARS-CoV-2}

Literatures show that about 70-80\% genome of SARS-CoV-2 is similar to that of SARS CoV. In addition, the target receptor for both the viruses is ACE-2 (Angiotensin-converting enzyme-2), through which the SARS-CoV-2 enters into the human cell to cause infection [13]. However, the difference in both SARS CoV and SARS-CoV-2 is that the SARS-CoV-2 spike binds to the ACE-2 with approximately about 10-20 fold higher affinity than the SARS $\mathrm{CoV}$, thus making the virus to undergo easy replication in the human body. When the SARS-CoV-2 initially enters into the alveolar epithelial cells, it undergoes replication and stimulates a strong immune response which leads to cytokine storm syndrome (hypercytokinemia) and pulmonary tissue damage. Hypercytokinemia is due to the uncontrolled production of pro-inflammatory mediators and plays an important role in acute respiratory distress syndrome and failure of multiple organs [8].

The replication of SARS-CoV-2 after entering into the human body is given in (fig 3).

Initially, the virus enters the cell by attaching to the ACE- 2 receptor via endocytosis through a conformational change. After the initiation, the sense RNA (+) will be released. This RNA contains a $5^{\prime}$ prime and a 3'poly-A tail that will undergo translation.

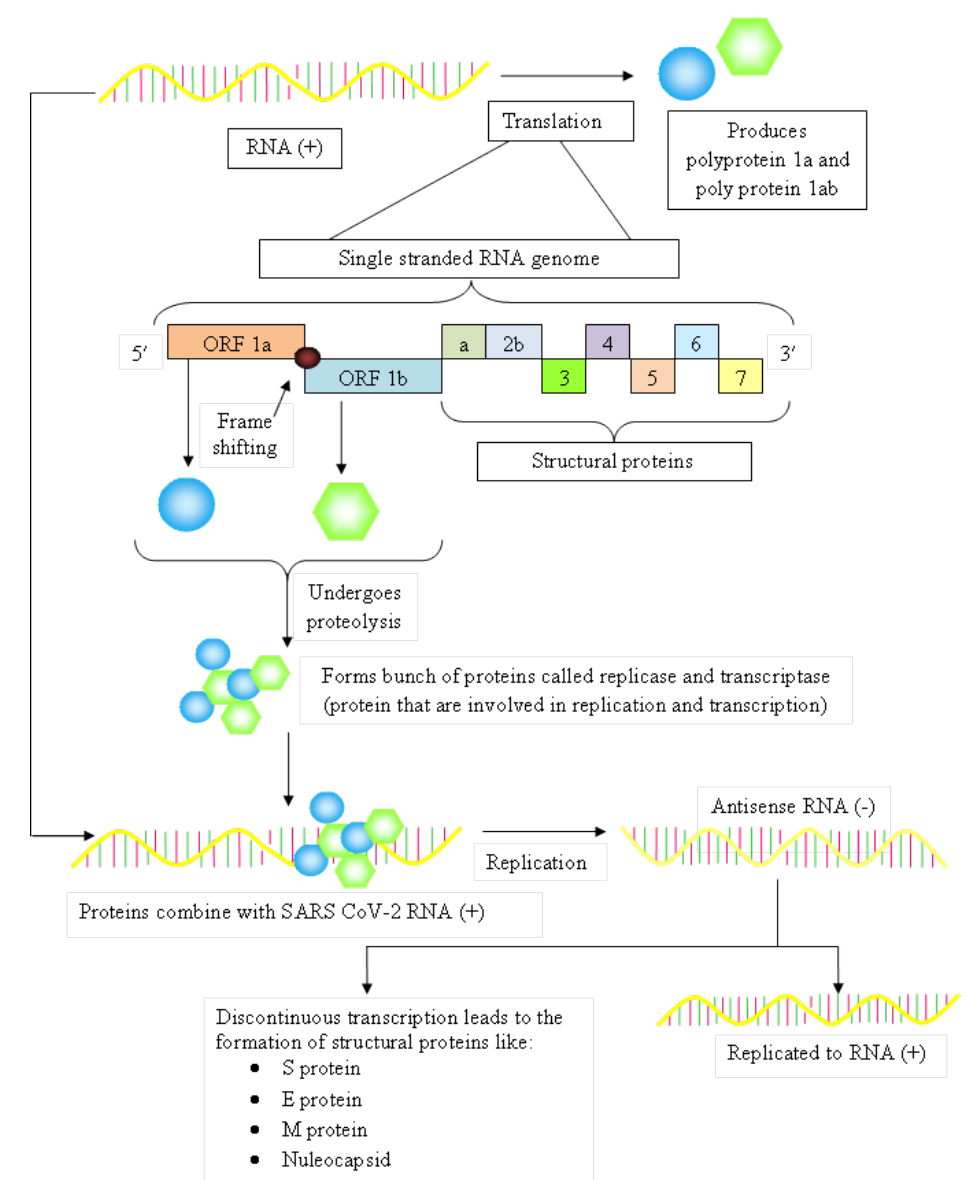

Fig. 4: Represents the formation of RNA (+) and structural protein form the invaded RNA

As given in (fig. 4), the ribosome present in the host cell will translate the ORF (open reading frames) to obtain the polyproteins, namely pp1a and pp1ab. After the formation of pp1a, there will be a frameshift, after which it will lead to the formation of pp1ab. These pp1a and pp1ab undergoes proteolysis to form a bunch of proteins, namely replicase protein and transcriptase protein that are involved in the replication and transcription process. These proteins combine with the RNA (+) and leads to the formation of anti-sense RNA via replication. The (-) RNA, undergoes a discontinuous transcription to form the structural protein as well as replication to form (+) RNA Later, the translation of structural proteins occurs in the endoplasmic reticulum. After which, the nucleocapsid, along with RNA (+) combines with the ER (intermediate compartment) and gets packed into the vesicle. Finally, the matured virion undergoes exocytosis and infects other healthy cells [3].

\section{Traditional medicines}

Many medicinal plants are available with anti-viral activity. When a researcher wants to develop an herbal formulation, it is important to understand about its taxonomy, ecology, conservation of herbs and the pathways associated with metabolite synthesis [14]

Vimalanathan et al. [15] worked on 30 different species of medicinal plant to determine the antiviral activity on 7 different viruses like herpes simplex virus, mouse coronavirus (a surrogate for human SARS virus), influenza virus and sindbis virus etc. In order to check the anti-viral activity, they have used 2 different methods, namely virucidal and pre-exposure protocol. They have concluded that every plant extract had an anti-viral activity to some extent. Additionally, the species like Gymnema sylvestre, Pergularia daemia, Clitoria ternatea L., Leucas aspera, Cassia alata, Evolvulus alsinoides, Vitex trifolia and Clerodendrum inerme had shown an impressive result than other extracts. They have stated that the vulnerability of mouse coronavirus and influenza virus suggests that these plant extracts could also be used in controlling respiratory infections.

While coming to the Traditional Chinese Medicine (TCM), National Health of Commission of China recommends the Chinese medicine decoctions [14]. 
A study has been worked on the evidence for recommending Chinese medicine with the help of ancient classics and human studies. They have obtained the research evidence data from the clinical trials, cohort studies and other population studies using Chinese medicine (CM) for preventing communicable respiratory virus diseases. They have utilized 3 studies using CM for the prevention of SARS and 4 studies for H1N1 influenza. For the prevention of COVID-19, 23 provinces issued CM programme in China. They have counted the frequency of the herbs used in the CM formulae in which it has 54 different herbs out of which 19 were repeated for 3 or more times. The top 2 herbs include Radix astragali and Glycyrrhizae Radix Et Rhizoma. Finally, they have concluded that based on the historical evidence and human evidence of SARS and H1N1 influenza prevention, Chinese herbal formula would be an alternative approach for the prevention of COVID-19 in the high-risk population [16].

Li S Y et al., [17] has stated that the extracts from Lycoris radiate, Artemisia annua and Lindera aggregate produced anti-viral activity against SAR CoV. In addition, the Isatis indigotica root was also tested against the SARS CoV. In which, the researcher have checked the antiSARS CoV 3C-like protease (chymotrypsin-like protease) effect of Isatis indigotica root. As the $3 \mathrm{C}$ like protease is responsible for the proteolysis of replicase polypeptides $1 \mathrm{a}$ and $1 \mathrm{ab}$ into a functional protein, they have targeted this particular 3C like protease [18].

A study has been conducted on Torreya nucifera, to find out its inhibitory activity on SARS-CoV 3C like protease. The researchers have isolated 12 phytochemicals from Torreya nucifera to find out their inhibitory action against SARS CoV 3CLpro via the enzymatic inhibition assay. From the assay, they have said that the biflavonoid amentoflavone had an $\mathrm{IC}_{50}$ value of $8.3 \mu \mathrm{M}$. Thus, they state this particular biflavonoid as a potent inhibitor of SARS CoV 3CLpro [19].

Another study has been done on Houttuynia cordata against the SARS CoV. They have tested the effect of Houttuynia cordata for the immunomodulatory activity in mouse splenic lymphocytes; they have also determined their inhibitory effect on SARS CoV-3CL pro in dose-dependent manner using fluorogenic assay and RNA dependent RNA polymerase. As a result, the researcher state that the Houttuynia cordata water extract could induce the proliferation of splenic lymphocytes in the dose-dependent manner. Through flow cytometry, they state that the Houttuynia cordata increased the proportion of $\mathrm{CD}^{+}$, $\mathrm{CD} 8{ }^{+} \mathrm{T}$ cells [20].

From all these studies, we can clearly see that the natural compounds can act on the coronavirus in different mechanisms. But all the studies that were discussed in the previous session were only for the SARS $\mathrm{CoV}$. And as of now, we have seen the effect of Traditional medicine in the treatment of SARS CoV infection. While coming to SARS-CoV-2, TCM plays a vital role in the treatment. TCM can be an effective strategy for the treatment of various syndromes by adjusting the specific medicine for each patient. In addition, they can also be used in different stages of disease like prevention, treatment and rehabilitation. During the outbreak of COVID-19 in China, more than 3,100 medical staffs of TCM were dispatched to Hubei province [21]. Literature shows that the TCM scheme was included in the diagnosis and treatment guidelines for COVID-19 as given by the National Health Commission and State Administration of Traditional Chinese Medicine [21]. Later the TCM experts fully participated in the rescue process [22]. They have used decoctions, Chinese patent medicine, acupuncture and other therapies for the treatment based on the differentiation in the syndrome. 102 cases with mild symptoms treated with TCM showed the following parameters:

- The clinical symptom disappearance was shortened by $2 \mathrm{~d}$,

- The body temperature recovery time was shortened $1.7 \mathrm{~d}$,

- Stay in the hospital was shortened by $2.2 \mathrm{~d}$,

- $22 \%$ improvement rate in the CT image,

- $33 \%$ increase in the clinical cure rate and

- $70 \%$ increase in the lymphocytes was observed.

Thus, based on the overall symptoms, they have prescribed the prescription like:

\section{- Qingfei paidu decoction (QPD)}

\section{- Gancaoganjiang decoction}

- Sheganmahuang decoction

- Qingfei touxie fuzheng recipe etc.

The QPD has been prescribed for the diagnosis and treatment plan of COVID-19 in China. Ren et al. [22] also stated that the effective cure rate of QPD against the SARS-CoV-2 was $90 \%$. Through the functional enrichment analysis, they have said that the QPD could perform activities like inhibition and alleviation of excessive immune response and they can eliminate the inflammation through the immune-related pathway and cytokine action-related pathway. Finally, the author said that the treatment practice of COVID-19 showed that the early intervention of TCM is important to:

- Improve the cure rate,

- Lessen the course of disease,

- Delay in disease progression and

- Decrease the mortality rate.

An article published 2020 on TCM, states that the "Qing Fei Pai Du Tang" is screened by the "National Administration of Traditional Chinese Medicine" (NATCM) and have widely recommended nationwide. As said previously the effect of TCM differs in different stages of disease. Thus, before the administration of the treatment, the doctors diagnoses the syndrome based on the comprehensive analysis of signs and symptoms. This Qing Fei Pai Du Tang contains a total of 21 kinds of Chinese Medicines and they say that these compositions were derived from 4 different prescriptions. 21 herbs are given in (fig. 5) [23].

Another work has been carried out on the topic "Prevention and treatment of COVID-19 with Qingfei paidu decoction". They have collected data of COVID-19 patients treated with TCM and Qingfei paidu decoction in Shanxi, China. They have discussed about the efficacy of both TCM as well as the qing fei paidu decoction. It was said that qing fei paidu decoction, has a definite curative effect. While coming to the efficacy of Qingfei paidu decoction, the author has said that out of 76 discharged patients, 59 cases were treated with Qingfei paidu decoction and the mean hospitalization time was $11.3 \pm 4.2 \mathrm{~d}$. However, it has been concluded that the clinical efficacy of Qingfei paidu decoction needs to be studied further [24].

Kai Zhang says that since December 2019, the COVID-19 patients in China have been treated with integrated Chinese medicine and western medicine. The author says that most of the Chinese herbs can be divided into 3 categories like clearing heat, eliminating dampness and detoxification. It is given that; Qingfei paidu decoction has been used by 4 provincial hospitals in China to treat 214 patients with viral infection (COVID-19). They have taken $3 \mathrm{~d}$ as the course of treatment and the total effective rate has reached more than $90 \%$. Despite, in that particular study, they say that there were some methodological problems such as no control group, no mention about randomization, no blinding study, lack of long term efficacy and follow up etc. The author states that highquality evidence for the safety of some Chinese herbs are lacking. However, it is believed that there are no serious adverse reactions when they are used correctly [25].

Yang Y et al. [26] says that according to the current clinical guideline in China and based on the experience in the treatment of SARS CoV and MERS patients, both conventional medicine as well as TCM are used in the treatment of SARS-CoV-2. Since the target for the SARS$\mathrm{CoV}-2$ entry into the human cell is ACE-2 receptor which is similar to that of SARS CoV entry; thus the TCM having the capacity to target this receptor will prevent the SARS-CoV-2 infection. The article says that on $17^{\text {th }}$ February 2020, National Health Commission (NHC) of the People's Republic of China reported that 60,107 confirmed cases of COVID-19 patients had been treated with TCM. Even though the author has discussed about the TCM in the treatment of coronavirus; finally, they have said that the safety of the TCM used in the treatment of emerging coronavirus infections should be carefully evaluated in order to avoid toxicity or their interference with the efficacy of the conventional treatment methods. 


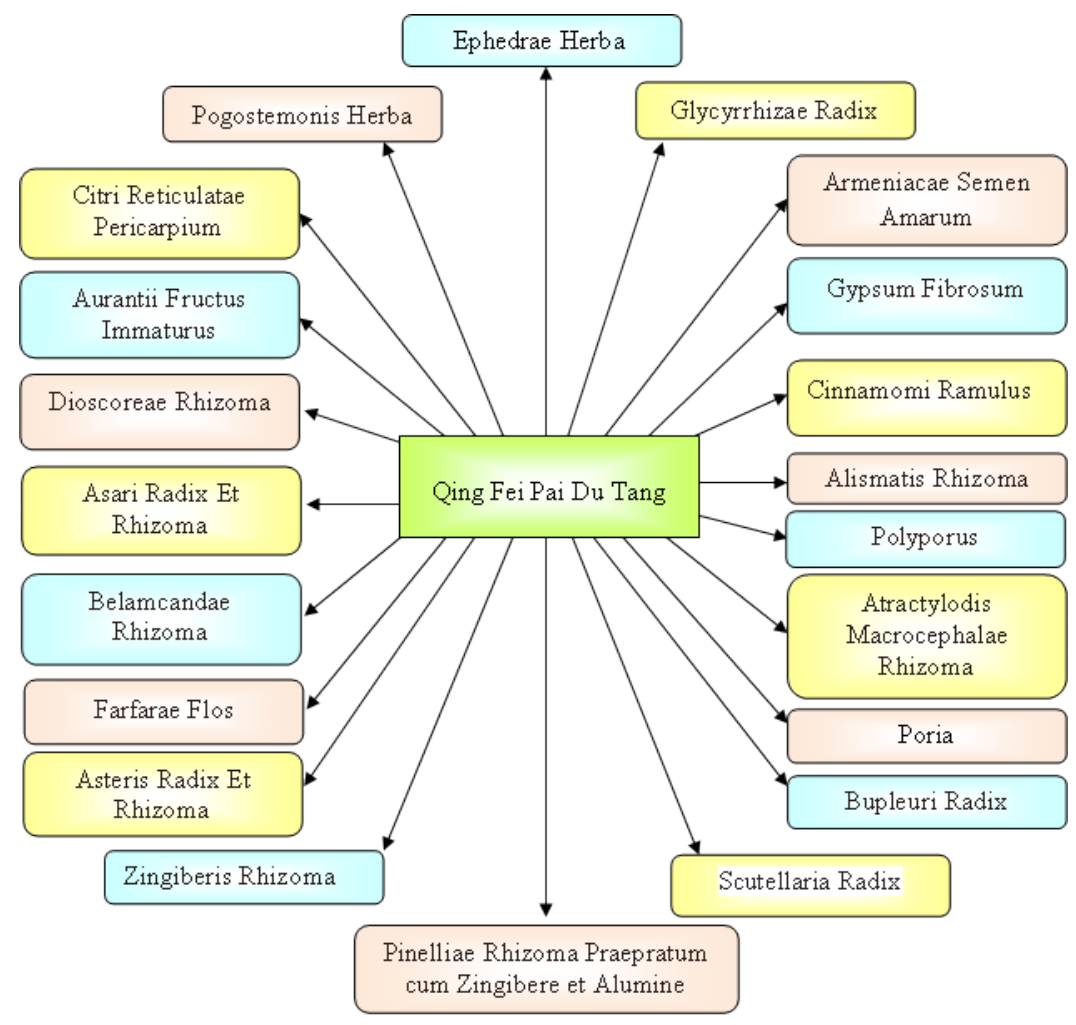

Fig. 5: Represents the composition of qingfei pai du tang decoction

\section{Effect of flavonoids and medicinal herb on COVID-19}

Flavonoids are natural compounds that are involved in various activities. They usually possess a polyphenolic structure and are found commonly in fruits, vegetables and in few beverages as well. They produce various health benefits and they are used in various nutraceuticals, pharmaceuticals, cosmetics and medicinal applications. It can possess various activities like anti-inflammatory, anti-oxidant, anti-microbial and anti-viral activities. It has been stated that flavonoids like quercetin, naringin, hesperetin and catechin possess anti-viral activity by affecting the replication and infectivity of certain RNA and DNA [27].

Apart from this, the flavonoids has also shown their activity against a variety of viruses, including poliovirus, astrovirus, HIV (human immunodeficiency virus), enterovirus, respiratory syncytical virus (RSV), parainfluenza virus type 3(PIV3), and influenza virus type A (Flu A)

Peterson [28] has worked on in silico modeling to find the binding potential of 72 flavonoids towards the main protease (3CLpro) of SARS-CoV and SARS CoV-2. The top 10 flavonoids recognized by him were amentoflavone, gallocatechin gallate, diosmin, epigallocatechin gallate, hidrosmin, catechin gallate, elsamitrucin, pectolinaren, quercetin and isoquercetin.

Furthermore, Adem et al. [29] have worked on natural polyphenols to identify the potent inhibitors of COVID-19 main protease with the aid of in silico modeling. In this study, they have tested different flavonoids to determine their inhibitory action against the main protease of SARS-CoV-2. The author has stated that the hesperidin showed the highest binding energy at the active site of the COVID19. Further, they state that hesperidin and rutin have better binding affinity towards the main protease of COVID-19. Hence, they conclude that the compounds are dietary foods, they can be biologically safe. However, further studies like in vitro and in vivo studies are required for the validation of these compounds.

Vellingiri et al. [30] have discussed about the COVID-19 and the current drugs available for their treatment. They have also shed a light on the Indian Medicinal plants and their possible effects on the COVID-19. In addition, they have stated that AYUSH has recommended few Indian medicinal plants as prevention and prophylaxis for COVID-19.

An in silico study has been done by Thuy BT et al., [31] with the aid of garlic on SARS CoV-2. They have determined the inhibiting capacity of essential garlic oil on ACE-2 as well as on PDB6LU7 (main protease of SARS-CoV-2). They have identified about 18 compounds in the essential oil using GC-MS (gas chromatographymass spectroscopy). Out of which 17 compounds were having the binding abilities. In addition, they state that, diallyl tetrasulfide and trisulfide, 2-propenyl propyl had best interaction with regions of ACE-2 protein. Finally, it was concluded that the synergistic activity of all the 17 compounds have served a good inhibition of both ACE-2 and PDB6LU7.

Another in silico study has been carried out by Thirumalaisamy Rathinavel; in order to check the effect of 6-gingerol on SARS-CoV-2. 6-gingerol is a bioactive phenolic phytocompound of ginger. Ginger is the herbaceous plant that possesses various activities like antiviral, anti-oxidant, antipyretic and analgesic properties. In silico studies revealed that 6-gingerol had excellent drug likeliness and very good pharmacokinetic properties. In addition, they have stated that it also had a high binding affinity of- $2.8764 \mathrm{KJ} / \mathrm{mol}$ to- 15.7591 $\mathrm{KJ} / \mathrm{mol}$ with multiple targets of SARS-CoV-2, including viral proteases, RNA binding protein and spike protein [32].

Apart from the above flavonoids, researchers are also being carried out to determine the effect of "Kabasura kudineer" against COVID19. Kabasura kudineer are said to be a polyherbal siddha formulation that can be used to treat a range of fever irrespective of the seasons.

Pitchiah Kumar et al. [33] worked on kabasura kudineer using in silico modeling to target the spike protein of novel coronavirus. They have stated that the kabasura kudineer is consisting of 15 herbal ingredients. All the ingredients (in Tamil names) along with their botanical names are given in the (table 1). 
Table 1: List of ingredients used in kabasura kudineer

\begin{tabular}{lll}
\hline S. No. & Tamil name & Botanical name \\
\hline 1. & Chukku & Zingiber Officinale \\
2. & Thippili & Piper longum \\
3. & Kirambu & Syzygium aromaticum \\
4. & Sirukanchori & Tragia involucrate \\
5. & Akkirakaram & Anacyclus pyrethrum \\
6. & Mulliver & Hygrophila auriculata \\
7. & Kadukkaithol & Terminalia chebula \\
8. & Adathodai & Adathoda vasica \\
9. & Karpuravalli & Coleus amboinicus \\
10. & Kostam & Saussurea lappa \\
11. & Seendhil & Tinospora cordifolia \\
12. & Siruthekku & Clerodendrum serratum \\
13. & Nilavembu & Andrographis paniculata \\
14. & Vattathiruppi & Sida acuta \\
15. & Korai kizhangu & Cyperus rotundus \\
\hline
\end{tabular}

The author has said that according to the rough and accurate docking, the major active phyto compounds that bind with the targets have been identified. List of major phytoconstituents are listed in (table 2).

Table 2: Includes the major phytoconstituents that target the spike protein

\begin{tabular}{lll}
\hline S. No. & Plant name & Phytoconstituent \\
\hline 1. & Andrographis paniculata & Andrographolide \\
2. & Hygrophila auriculata & Apigenin \\
3. & Syzygium aromaticum & Carvacrol \\
4. & Tragia involucrata & Costunolide \\
5. & Syzygium aromaticum & Eugenol \\
6. & Anacyclus pyrethrum & Pyrethrin \\
7. & Adhatoda vasica & Vasicine \\
8. & Tinospora cordifolia & Cordifolioside B \\
9. & Zingiber Officinale & Zingiberene \\
\hline
\end{tabular}

Another study has been carried out by Kiran et al. on Kabasura Kudineer with the help of in silico modeling to determine their activity against the spike protein of SARS CoV-2. Kabasura kudineer and JACOM (a novel drug patented in the year 2018) formulation were considered for their study. They have carried out molecular docking for 32 phytoconstituents of kabasura kudineer and 5 phyto constituents of JACOM. The binding affinity of the compounds against the target spike protein has been determined by the LF rank score. It was established that chrysoeriol and luteolin from kabasura kudineer and quercetin from JACOM formulations were having the low LF rank with high binding affinity. Further, in silico pharmacokinetic and toxicity studies were studied and as a result they have stated that all the phytoconstituents have good oral bioavailability and free from toxicity. Further, they have proposed a new formulation called SNACK-V containing 9 phytoconstituents from 6 herbal plants [34].

In addition to the above aspects, Ministry of AYUSH has recommended certain Ayurveda's immunity-boosting measures for self-care during the COVID-19 crisis. The recommendations are given in (table 3) [36]. Additionally, the meaning response for the safety measures has also discussed [37]. As discussed earlier, most of the components recommended by AYUSH have several activities against viral infections. Thus, the natural herbal compounds can be considered for further studies for the management of viral infections and diseases.

Table 3: Recommendations made by the ministry of AYUSH

\begin{tabular}{lll}
\hline S. No. & Measures & Meaning response \\
\hline 1. & General measures & Seen as cleansing the body \\
(i) Drink warm water throughout the day & Seen to promote physical fitness \\
(ii) Daily practice of Yogasana, Pranayama and meditation for at least $30 \mathrm{~min}$ & Seen as a health promoter and essential part \\
(iii) Recommended spices like haldi (turmeric), jeera (cumin), dhaniya (coriander) and & \\
lahsun (garlic) in cooking & Seen as rejuvenating body \\
Ayurvedic immunity promoting measures & Seen as a suitable remedy for cough and \\
(i) Taking Chyavanprash of 10 gm & respiratory problems \\
(ii) Drinking of herbal tea/decoction made of tulsi (basil), dalchini (cinnanmon), & Seen as fighting against cold and cough \\
kalimirch(black pepper), shunthi (dry ginger) and munakka (raisins) once/twice a day & \\
(iii) Uptake of golden milk (made up of turmeric and milk) & Seen as a healing substance \\
Simple Ayurvedic procedures & Seen as a remedy for various ailments \\
(i) Nasal application: Applying of sesame oil or coconut oil or ghee in both the nostrils & \\
(ii) Oil pulling therapy: Swishing 1 tablespoon sesame/coconut oil in mouth for 2-3 min & Seen as effective against respiratory problems \\
Dry cough/Sore throat & Seen as a treatment for the throat diseases \\
(i) Steam inhalation with fresh pudina (mint) leaves or ajwain (caraway seeds) &
\end{tabular}

\section{Current scenario and future aspects}

The whole world is now fighting with COVID-19. When a disease is not contagious, people no need to worry much. However, when it is a communicable disease, it has to be taken into consideration. In the current circumstances, scientists from all over the world are putting their full effort to develop an effective therapy for rehabilitation. But unfortunately, the results aren't satisfying and successful. The 
reason for this failure may be due to the pitfalls present during the development of drug or vaccine-like side effects, toxicity, multidrug resistance, efficacy and so on. Most of the researchers now are working on conventional medicine and they had also given satisfying results. Even then, we should not forget about our traditional medicines. Many traditional medicines are now being forgotten by us. However, scientists are working on combination therapy using both western as well as traditional medicine. This has also given promising results by producing synergistic activity and lessening the side effects. Though traditional medicines are giving anticipated results, their safety has to be taken into account. For which we need to undergo a thorough examination. Besides, we should also consider the various aspects of the disease including the symptoms, stages and severity in different individuals. However, currently clinical trials for traditional medicines in management of COVID-19 are also being carried out by the researchers [35]. As said by the one of the most outstanding fig. in the history of medicine "Let food be your medicine and medicine be your food". Keeping this particular quote in mind hope we can wisely fight against various diseases.

\section{DISCUSSION}

SARS-CoV-2 is a life-threatening disease that emerged from Wuhan, China and now it is affecting worldwide. The disease is leading to severe outbreaks mainly because of human-to-human transmission. The evolution of the infection after entering the human body starts once the spike protein (s-protein) binds to the ACE-2 receptor. So, researches are being carried out to inhibit this binding. However, previous studies have also been carried out for targeting SARS CoV $3 \mathrm{CL}^{\mathrm{pro}}$ as they are responsible for the proteolysis of polypeptides $1 \mathrm{a}$ and $1 \mathrm{ab}$ to form functional proteins. Thus, studies are also in progress for targeting the $3 \mathrm{CL}^{\text {pro }}$ (chymotrypsin-like protease). As discussed earlier, the virus enters into the alveolar epithelial cells and stimulates a strong immune response which leads to cytokine storm syndrome (hypercytokinemia). This is usually due to the uncontrolled production of pro-inflammatory mediators, which can lead to a fatal condition. But even this condition can be managed by considering the herbal formulation. Because most of the medicinal plants have anti-inflammatory properties that have the ability to inhibit the production of pro-inflammatory mediators, thus, it may help in the management of cytokine storm syndrome. In this article, we have discussed about the virus, its replication and few traditional medicines involved in the prevention and management of emerging coronavirus infection. Mainly we have focused on TCM because they are previously involved in treating various diseases like SARS CoV and MERS CoV infections. When we look into the literature, the most commonly used TCM against SARS-CoV-2 is Qingfei paidu decoction. Even though literatures are available for the use of Qingfei paidu decoction against COVID-19. Further studies are required to understand the clinical efficacy of Qingfei paidu decoction. In addition, this type of herbal formulations can be administered to the patients only after a thorough understanding of the disease symptoms and severity, which will vary from patient to patient. Moreover, the TCM has been combined with western medicine in some of the studies to get better efficacy. Thus, even though literatures are available stating the use of TCM in the management of COVID-19, further detailed studies are required to determine their safety and efficacy in the treatment of emerging coronavirus. In addition, we have also shed a light on Kabasura kudineer and their binding affinity by in silico modeling used in the management of COVID-19.

\section{CONCLUSION}

COVID-19 is a life-threatening disease that is affecting most of the people around the world in a contagious manner. Even though various medications and vaccines are in different stages of development, exact remedy for eradicating the COVID-19 are yet to be discovered. In that manner, herbal formulations can also be considered for the management of SARS CoV-2. Since herbal plants possess various medicinal uses and has been used for the treatment of various diseases. They can also be considered in the current situation. To conclude, traditional medicines can heal various diseases irrespective of communicable or non-communicable disease. Thus, traditional medicine can be considered for the management of novel coronavirus infection as a monotherapy or combination therapy after a thorough investigation on their safety, efficacy and toxicity etc.

\section{ACKNOWLEDGMENT}

We acknowledge the generous research infrastructure and supports from JSS College of Pharmacy, JSS Academy of Higher Education and Research, Rocklands, Ooty, The Nilgiris, Tamilnadu, India.

\section{FUNDING}

Nil

\section{AUTHORS CONTRIBUTIONS}

All the authors have contributed equally.

\section{CONFLICT OF INTERESTS}

Declared none

\section{REFERENCES}

1. Zheng J. SARS-CoV-2: an emerging coronavirus that causes a global threat. Int J Biol Sci 2020;16:1678.

2. National Institute of Allergy and infectious disease. COVID-19, MERS and SARS. Available from: https://www.niaid.nih.gov/ diseases-conditions/covid-19. [Last accessed on 29 Mar 2020].

3. Cascella M, Rajnik M, Cuomo A, Dulebohn SC, Di Napoli R. Features, evaluation and treatment coronavirus (COVID-19). In: Statpearls [internet]; 2020.

4. Lai CC, Wang CY, Wang YH, Hsueh SC, Ko WC, Hsueh PR. Global epidemiology of coronavirus disease 2019: disease incidence, daily cumulative index, mortality, and their association with country healthcare resources and economic status. Int J Antimicrob Agents 2020;55:105946.

5. WHO a. Coronavirus disease (COVID-19) pandemic. Available from: https://covid19.who.int/. [Last accessed on 11 Oct 2020]

6. WHO b. WHO Coronavirus Disease (COVID-19) Dashboard. Available from: https://covid19.who.int/. [Last accessed on 30 Nov 2020].

7. Rothan HA, Byrareddy SN. The epidemiology and pathogenesis of coronavirus disease (COVID-19) outbreak. J Autoimmun 2020;109:102433.

8. Li H, Liu SM, Yu XH, Tang SL, Tang CK. Coronavirus disease 2019 (COVID-19): current status and future perspective. Int J Antimicrob Agents 2020;55:105951.

9. WHO c. Qand a on coronavirus disease (COVID-19). Available from: https://www.who.int/news-room/q-a-detail/q-a-coronaviruses. [Last accessed on 30 Mar 2020].

10. Zhai P, Ding Y, Wu X, Long J, Zhong Y, Li Y. The epidemiology, diagnosis and treatment of COVID-19. Int J Antimicrob Agents 2020;55:105955.

11. Lu H. Drug treatment options for the 2019-new coronavirus (2019-nCoV). Biosci Trends 2020;14:69-71.

12. Clinicaltrial.gov. Available from: https://clinicaltrials.gov/ct2/ results?cond=Covid +19 andterm $=$ and cntry=andstate=andcity $=$ and dist $=$ [Last accessed on 09 Oct 2020]

13. Ceccarelli M, Berretta M, Rullo EV, Nunnari G, Cacopardo B. Editorial-Differences and similarities between severe acute respiratory syndrome (SARS)-CoronaVirus (CoV) and SARSCoV-2. Would a rose by another name smell as sweet? Euro Rev Med Pharmacol Sci 2020;24:2781-3.

14. Redeploying plant defences. Nat Plants 2020;6:177.

15. Vimalanathan S, Ignacimuthu S, Hudson JB. Medicinal plants of Tamil Nadu (Southern India) are a rich source of antiviral activities. Pharm Biol 2009;47:422-9.

16. Luo H, Tang QL, Shang YX, Liang SB, Yang M, Robinson N, et al. Can Chinese medicine be used for prevention of coronavirus disease 2019 (COVID-19)? A review of historical classics, research evidence and current prevention programs. Chin J Integr Med 2020;26:243-50.

17. Li SY, Chen C, Zhang HQ, Guo HY, Wang H, Wang L, et al. Identification of natural compounds with antiviral activities against SARS-associated coronavirus. Antiviral Res 2005;67:18-23. 
18. Lin CW, Tsai FI, Tsai CH, Lai CC, Wan L, Ho TY, et al. Anti-SARS coronavirus 3C-like protease effects of Isatis indigotica root and plant-derived phenolic compounds. Antiviral Res 2005; 68:36-42

19. Ryu YB, Jeong HJ, Kim JH, Kim YM, Park JY, Kim D, et al. Biflavonoids from Torreya nucifera displaying SARS-CoV 3CLpro inhibition. Bioorg Med Chem 2010;18:7940-7.

20. Lau KM, Lee KM, Koon CM, Cheung CS, Lau CP, Ho HM, et al. Immunomodulatory and anti-SARS activities of Houttuynia cordata. J Ethnopharmacol 2008;118:79-85.

21. China daily.com Available from: https://www.chinadaily.com.cn/ pdf/2020/1.Clinical.Protocols.for.the.Diagnosis.and.Treatment. of.COVID-19.V7. [Last accessed on $03 \mathrm{Apr}$ ]

22. Ren JL, Zhang AH, Wang XJ. Traditional Chinese medicine for COVID-19 treatment. Pharmacol Res 2020;155:104743.

23. Hong Zhi DU, Xiao Ying HO, Yu-Huan MI, Huang BS, Da-Hui LI. Traditional Chinese medicine: an effective treatment for 2019 novel coronavirus pneumonia (NCP). Chin J Nat Med 2020;18:206-10

24. Liu N, Li S, Fan K, Lu T, Li T. The prevention and treatment of COVID-19 with Qingfei Paidu decoction in shanxi China. TMR Modern Herbal Medicine; 2020. P. 1.

25. Zhang K. Is traditional Chinese medicine useful in the treatment of COVID-19? Am J Emerg Med 2020;38:2238.

26. Yang Y, Islam MS, Wang J, Li Y, Chen X. Traditional Chinese medicine in the treatment of patients infected with 2019-new coronavirus (SARS-CoV-2): a review and perspective. Int J Biol Sci 2020;16:1708.

27. Panche AN, Diwan AD, Chandra SR. Flavonoids: an overview. J Nutr Sci 2016;5:e47.

28. Peterson L. COVID-19 and flavonoids: In silico molecular dynamics docking to the active catalytic site of SARS-CoV and SARS-CoV-2 Main Protease; 2020
29. Adem S, Eyupoglu V, Sarfraz I, Rasul A, Ali M. Identification of potent COVID-19 main protease (Mpro) inhibitors from natural polyphenols: an in silico strategy unveils a hope against CORONA; 2020. DOI:10.20944/preprints202003.0333.v1

30. Vellingiri $B$, Jayaramayya $K$, Iyer $M$, Narayanasamy $A$, Govindasamy V, Giridharan B, et al. COVID-19: a promising cure for the global panic. Sci Total Environ 2020;725:138277.

31. Thuy BT, My TT, Hai NT, Hieu LT, Hoa TT, Thi Phuong Loan H, et al. Investigation into SARS-CoV-2 resistance of compounds in garlic essential oil. ACS omega 2020;5:8312-20.

32. Rathinavel T, Palanisamy M, Palanisamy S, Subramanian A, Thangaswamy S. Phytochemical 6-gingerol-a promising drug of choice for COVID-19. Int J Adv Sci Eng 2020;6:1482-9.

33. Pitchiah Kumar M, Meenakshi Sundaram K, Ramasamy MS Coronavirus spike (S) glycoprotein (2019-ncov) targeted siddha medicines kabasura kudineer and thonthasura kudineer-in silico evidence for corona viral drug. Asian J Pharm Res Health Care 2020;12:20-7.

34. Kiran G, Karthik L, Devi S, Sathiyarajeswaran P, Kanakavalli K, Kumar KM, et al. In silico computational screening of kabasura kudineer-official siddha formulation and JACOM against SARSCoV-2 spike protein. J Ayurveda Integr Med 2020. https://doi.org/10.1016/j.jaim.2020.05.009

35. ClinicalTrials.gov. Available from: https://clinicaltrials.gov/ ct2/results?cond=COVID19andterm=traditional+medicineandc ntry $=$ andstate $=$ andcity $=$ anddist $=$. [Last accessed on 01 Nov 2020].

36. AYUSH T. Ayurveda's immunity boosting measures for self-care during COVID 19 crisis. YaN The Ministry of Ayurvedic, Unani, Siddha and Homeopathy (AYUSH), editor; 2020.

37. Rajkumar RP. Ayurveda and COVID-19: where psychoneuroimmunology and the meaning response meet. Brain, Behavior, and Immunity; 2020. 